\title{
JENIS DAN POPULASI SERANGGA HAMA PADA BERAS DI GUDANG TRADISIONAL DAN MODERN DI PROVINSI GORONTALO
}

\section{SPECIES AND INSECT PESTS POPULATION ON RICE IN THE TRADITIONAL AND MODERN WAREHOUSE IN PROVINCE OF GORONTALO}

\author{
Jems llato'), M. F. Dien²) dan C. S. Rante ${ }^{3)}$ \\ 1)Balai Proteksi Tanaman Pangan dan Hortikultura Provinsi Gorontalo \\ 2)Perhimpunan Entomologi Indonesia Cabang Manado, Sulawesi Utara \\ 3)Fakultas Pertanian, Universitas Sam Ratulangi
}

\begin{abstract}
The quality and quantity of rice as a source of food for most of Indonesian people are closely connected with the activity of insect pests in Warehouse. This study aims to determine the species and insect pests populations on Rice at Traditional and Modern Warehouse in Province of Gorontalo. The study used a survey method shelter/rice warehouse in Mootilango district, Boliohuto District, and Tolangohula district, Gorontalo province. Sampling was conducted in a purposive sampling is to take a sample of the suspected rice pests. Sampling was carried out 4 times with a time interval of 2 weeks. The research found six species of insect pests on rice commodities in Gorontalo regency consisting of 5 species of the order Coleoptera and 1 type of the order Lepidoptera. The results show that the identification of insect pests found are Sitophilus oryzae (Coleoptera; Curculionidae), Tribolium castaneum (Coleoptera: Tenebrionidae), Carpophilus hemipterus (Coleoptera: Nitidulidae) Oryzaephilus sp. (Coleoptera; Silvanidae), Ahasverus sp. (Coleoptera; Cucujidae), Corcyra cephalonica (Lepidoptera; Pyralidae). Average highest pest insect populations, respectively S. oryzae (54.60 individuals), Tribolium sp. (13.85 individuals), Oryzaephilus sp. (4.52 individuals), Ahasverus sp. (3.42 individuals), Corcyra sp. (2.42 individuals) and $\mathrm{C}$. hemipterus (6.94 individuals), while the highest populations of insect pests found in traditional 16.40 modern warehouses 12.34 individual
\end{abstract}

Keywords : insect pests, rice, traditional and modern werehouse

\section{ABSTRAK}

Kualitas dan kuantitas beras sebagai sumber bahan pangan bagi sebagian besar masyarakat Indonesia erat hubungannya dengan aktifitas serangga hama dipenyimpanan. Penelitian ini bertujuan untuk mengetahui jenis-jenis serangga hama yang menyerang komoditas beras pada gudang tradisional dan modern di Provinsi Gorontalo. Penelitian menggunakan motode survei pada tempat penampungan / gudang beras di Kecamatan Mootilango, Kecamatan Boliohuto, dan Kecamatan Tolangohula, Kabupaten Gorontalo, Provinsi Gorontalo. Pengambilan sampel dilakukan secara "purposive sampling" yaitu dengan mengambil sampel berupa beras yang diduga terserang hama. Pengambilan sampel dilakukan sebanyak 4 kali dengan interval waktu 2 minggu sekali. Hasil penelitian ditemukan enam jenis serangga hama pada komoditi beras di Kabupaten Gorontalo yang terdiri dari 5 jenis dari ordo Coleoptera dan 1 jenis dari ordo Lepidoptera. Hasil identifikasi menunjukkan bahwa serangga hama yang ditemukan adalah Sitophilus sp. (Coleoptera; Curculionidae), Tribolium castaneum (Coleoptera: Tenebrionidae), Carpophilus hemipterus (Coleoptera: Nitidulidae) Oryzaephilus sp. (Coleoptera; Silvanidae), Ahasverus sp. (Coleoptera; Cucujidae), dan Corcyra cephalonica (Lepidoptera; Pyralidae). Rata-rata populasi serangga hama tertinggi berturut-turut adalah Sitophilus sp. (54,60 individu), Tribolium sp. (13,85 individu), Oryzaephilus sp. (4,52 individu), Ahasverus sp. (3,42 individu), Corcyra sp. (2,42 individu) dan Carpophilus sp. (6,94 individu); sedangkan populasi serangga hama tertinggi terdapat pada gudang tradisional 16,40 individu dan gudang modern 12,34 individu

Kata kunci : Serangga hama, beras, gudang tradisional dan modern 


\section{PENDAHULUAN}

Beras yang disimpan di dalam gudang tradisional maupun gudang modern sering mendapat gangguan dari serangga hama. Gangguan tersebut dapat menyebabkan terjadinya kerusakan dan kehilangan berat bahan. Besarnya kerusakan dan kehilangan tergantung dari cara serangga hama menyerang atau merusak. Produk pascapanen merupakan bagian tanaman yang dipanen dengan berbagai tujuan terutama untuk memberikan nilai tambah dan keuntungan bagi petani maupun konsumen (Wagianto, 2008).

Hama biasanya melubangi gabah dan memakan beras yang berada di dalamnya. Apabila gabah tersebut digiling maka beras yang dihasilkan akan pecah-pecah dan mengalami susut yang relatif besar. Akibat dari serangan hama pasca panen tersebut beras atau gabah akan menjadi berlubang kecil-kecil, karena beras atau gabah tersebut disimpan dalam jangka waktu yang relatif lama maka beras atau gabah tersebut menjadi butiran, pecah dan remuk bagaikan tepung (Harahap, 2003).

Menurut FAO (1974) dalam Manueke (1993) Kerusakan pada bahan pascapanen atau bahan simpanan sangat berarti dan mempunyai nilai penting dalam arti ekonomi karena: (1) bahan tersebut siap dikonsumsi, (2) menghabiskan biaya yang cukup banyak yaitu mulai dari pembenihan, pengolahan tanah, penanaman, pemeliharaan dan panen. Jadi, kerusakan yang sedikit pada bahan pascapanen sudah merupakan kerugian yang besar dibandingkan dengan serangan organisme pengganggu pada tanaman dipertanaman. Selain itu akibat lain dari adanya infestasi yang mengakibatkan terjadinya perubahan pada bahan pascapanen seperti perubahan warna dan rasa serta bau yang tidak enak atau terkontaminasi dengan penyakit yang terbawa oleh organisme tersebut.

Serangga yang paling banyak anggotaanggotanya sebagai hama pascapanen adalah dari ordo Coleoptera, ordo Lepidoptera, ordo Hymenoptera, dan ordo Hemiptera. Dari keempat ordo serangga tersebut Ordo Coleoptera adalah kelompok serangga yang terbanyak memiliki anggota-anggotanya sebagai hama pascapanen (Pranata,1982; Munro, 1986).

Menurut Pranata (1982), beberapa hama penting yang merusak komoditi beras di Indonesia antara lain, Sitophilus oryzae (Coleoptera; Curculionidae), Rhizopertha dominica (Coleoptera; Bostrychidae), Tribolium castaneum (Coleoptera; Tenebrionidae), Cryptolestes ferrugineus (Coleoptera; Cucujidae), Tenebroides mauritanicus (Coleoptera; Trogosstidae), dan Corcyra cephalonica (Lepidoptera; Pyralidae).

Penelitian bertujuan untuk mengetahui jenis-jenis serangga hama yang menyerang komoditas beras pada gudang tradisional dan modern di Provinsi Gorontalo. Dengan mengetahui jenis-jenis serangga hama yang berasosiasi pada komoditas beras digudang tradisional dan modern diharapkan dapat digunakan sebagai acuan dalam upaya pengendaliannya.

\section{METODE PENELITIAN}

Penelitian dilaksanakan di gudang tradisional dan gudang modern di Kabupaten Gorontalo, Provinsi Gorontalo. Penelitian menggunakan metode survei pada tempat penampungan/gudang beras di Kecamatan Mootilango, Kecamatan Boliohuto, dan Kecamatan Tolangohula, Kabupaten Gorontalo, Provinsi Gorontalo.

Pengambilan sampel dilakukan secara purposive sampling yaitu dengan mengambil sampel berupa beras yang diduga terserang hama. Kriteria sampel terserang hama ditandai dengan terdapatnya serangga pada sampel dan ataupun adanya gejala serangan serangga hama pada sampel yaitu adanya serbuk sisa gerekan pada beras. Sampel beras diambil pada bagian sudut dan bagian tengah (diagonal) yang masing-masing sebanyak 250 gram, kemudian dimasukkan ke dalam stoples dan disungkup dengan kain kasa halus. Pengambilan sampel dilakukan sebanyak 4 kali dengan interval waktu 2 minggu sekali. Masingmasing sampel diberi label sesuai tempat pengambilannya, kemudian dibawa ke laboratorium untuk diamati. Sampel beras diamati seminggu sekali selama 1 bulan. Hal-hal yang diamati adalah: 


\section{Jenis Serangga Hama}

Serangga hama yang ditemukan disortir/ dipisahkan menurut jenis dan lokasi pengambilannya. Sampel hama dikoleksi di dalam alkohol $70 \%$ untuk diidentifikasi. Identifikasi serangga hama dilakukan di Laboratorium Hama dan Penyakit Tumbuhan, Fakultas Pertanian, Universitas Sam Ratulangi, Manado. Identifikasi serangga hama menggunakan bahan pustaka Kamel and Hassaneim (1967), Hinton and Corbet (1975), Banks (1979), Halstead (1986), Haines (1991), Brower (2003) dan Buntin, et.al. (2003).

\section{Populasi Serangga Hama}

Serangga yang ditemukan disortir/pisahkan kemudian dihitung jumlahnya. Untuk menghitung rata-rata populasi hama digunakan formula sebagai berikut :

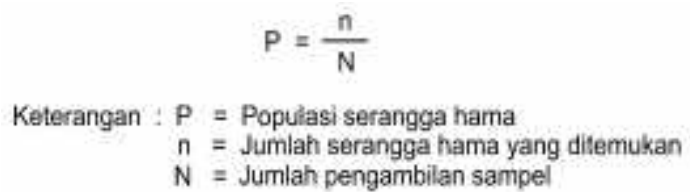

\section{HASIL DAN PEMBAHASAN}

\section{Jenis Serangga Hama}

Hasil penelitian ternyata terdapat enam jenis serangga hama pada komoditi beras di Kabupaten Gorontalo yang terdiri dari 5 jenis dari ordo Coleoptera dan 1 jenis dari ordo Lepidoptera. Hasil identifikasi berdasarkan ciri-ciri yang dilihat baik dari ukuran tubuh, warna, mata mejemuk, tungkai, sayap dan antena menunjukkan bahwa serangga-serangga tersebut adalah :

\section{Sitophilus oryzae}

Imago berwarna coklat kemerahan dan memiliki bintik-bintik coklat kemerahan. Pada sayap bagian depannya terdapat empat buah bintik berwarna kuning kemerahan yang membentuk corak yang khas. Tubuh imago berbentuk lonjong dan berukuran panjang berkisar 2-3,5 mm dan lebar 1,1-1,3 mm. Memiliki moncong dan terdapat antena yang berbentuk Lamellate (Gambar 1).

Hama ini diklasifikasikan ke dalam Filum Arthropoda, Sub-filum Mandibulata, Klas Insecta,
Sub-klas Pterygota, Ordo Coleoptera, Family Curculionidae, genus Sitophilus dan spesies $S$. oryzae (Anonim, 2009; Halstead, 1986; Brower, 2003).

\section{Tribolium castaneum}

Imago berwarna coklat merah kehitaman berukuran panjang kira-kira 5-6,5 mm dan lebar 2 $\mathrm{mm}$. Antena berbentuk clavate menyerupai gada, ruas-ruas membesar secara teratur dari arah pangkal ke ujung. Imago mempunyai antena berbentuk menyerupai gada dan melebar ke arah ujung secara beraturan (Gambar 3). Hama ini dijumpai pada setiap lokasi sampel. Serangga ini diklasifikasikan ke dalam phylum Arthropoda, Sub-phyllum Mandibulata, Kelas Insecta, Sub-klas Pterygota, Ordo Coleoptera, Famili Tenebrionidae, Genus Tribolium dan spesies T. castaneum (Ebeling, 2002; Buntin et.al., 2003; Halstead, 1986; Hinton, and Corbet. 1975; Munro, 1986).

\section{Carpophilus hemipterus}

Imago berwarna coklat tua kehitaman, berukuran panjang kira-kira 1,5 $\mathrm{mm}$ dan lebar 1 $\mathrm{mm}$. Sayap depan (elytra) pendek atau tidak menutupi seluruh abdomen sehingga terlihat beberapa ruas bagian ujung abdomen. Antena membesar pada 3 ruas terakhir sehingga menyerupai gada atau berbentuk capitates (Gambar 3). Serangga ini diklasifikasikan ke dalam phylum Arthropoda, Sub-phyllum Mandibulata, Kelas Insecta, Sub-klas Pterygota, Ordo Coleoptera, Famili Nitidulidae, Genus Carpophilus dan spesies C. hemipterus (Anonim, 2003; Ebeling, 2002; Halstead, 1986).

\section{Oryzaephilus sp.}

Imago berwarna coklat tua kemerahan berukuran panjang kira-kira 1-2 mm dan lebar 0,5$0,6 \mathrm{~mm}$. Tubuh agak langsing dan pipih, terdapat gerigi sebanyak 6 pasang pada masing-masing samping prothoraks. Kepala berbentuk menyerupai segitiga, terdapat garis-garis membujur pada elytra dan prothoraxnya. Antenna yang berbentuk Clavate (Gambar 4). Hama ini ditemukan pada setiap lokasi sampel. Serangga ini diklasifikasikan ke dalam 
phylum Arthropoda, Sub-phyllum Mandibulata, Kelas Insecta, Sub-klas Pterygota, Ordo Coleoptera, Famili Silvanidae, Genus Oryzaephilus (Hinton, and Corbet. 1975; Munro, 1986).

\section{Ahasverus sp.}

Imago berwarna coklat kemerah-merahan dan berukuran panjang kira-kira 2-3 $\mathrm{mm}$. kedua tepi anterior dari protoraks terdapat tonjolan seperti gigi. Antena terdiri dari 11 ruas dengan bentuk gada dan memiliki tarsi 5 ruas (Gambar 5). Hama ini ditemukan pada setiap lokasi sampel. Serangga ini diklasifikasikan ke dalam phylum Arthropoda, Subphyllum Mandibulata, Kelas Insecta, Sub-klas Pterygota, Ordo Coleoptera, Famili Cucujidae,
Genus Ahasverus (Anonim, 2008; Ebeling, 2002; Halstead, 1986).

\section{Corcyra cephalonica}

Imago berwarna kelabu dengan pertulangan sayapnya lebih gelap dari pada membrannya. Antena bertipe filiform dengan labial palpus yang lurus. Tungkai palsu larva berbentuk kerucut. Imago jantan memiliki bentuk tubuh lebih kecil dibandingkan dengan imago betina (Gambar 6). $C$. cephalonica masuk dalam golongan Animalia, Phylum Arthropoda, Sub Phylum Mandibulata Kelas Insakta, Sub Kelas Pterygota, Ordo Lepidoptera, Famili Pyralidae, Genus Corcyra, Spesies C. cephalonica Stainton (Kamel and Hassaneim, 1967; Mbata, 1989).
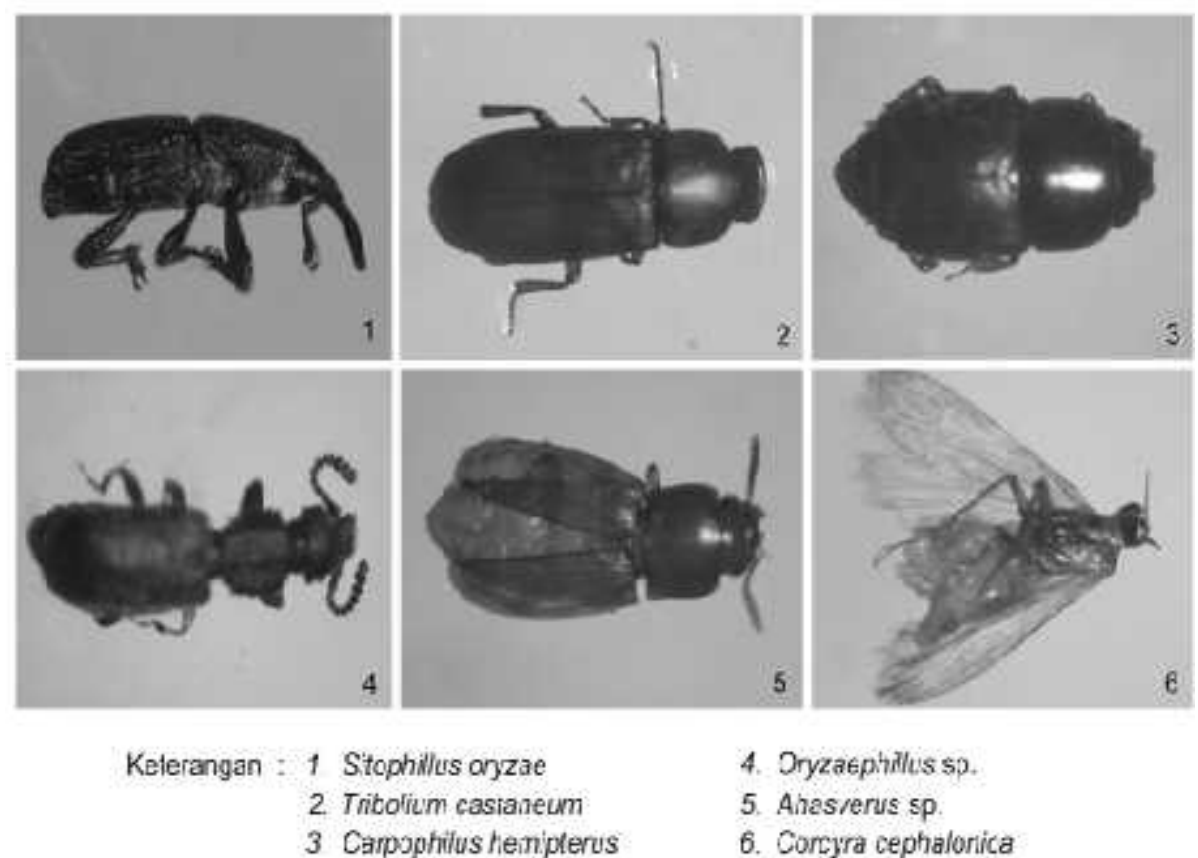
4. Oryzatphinlus sp.
5. Ahaskerus sp.
6. Corcyra cephalorica

Gambar 1. Jenis Serangga Hama pada Komoditi Beras di Provinsi Gorontalo

(Picture 1. Species Insect Pests on Rice Commodities in Province of Gorontalo)

Tabel 1. Rata-rata Populasi Serangga Hama pada Beras di Kabupaten Gorontalo

(Table 1. Density Population of the Insect Pests on Rice Commodity in Province of Gorontalo)

\begin{tabular}{lcccc}
\hline \multirow{2}{*}{ Jenis hama } & \multicolumn{3}{c}{ Lokasi sampel / Kecamatan (individu) } & \multirow{2}{*}{ Rata-rata } \\
\cline { 2 - 4 } & Mootilango & Tulangohula & Boliyohuto & \\
\hline Sitophilus sp. & 62,73 & 51,49 & 49,59 & 54,60 \\
T. castaneum & 14,40 & 12,93 & 14,24 & 13,85 \\
Carpophilus sp. & 7,30 & 6,99 & 6,55 & 6,94 \\
Oryzaephilus sp. & 4,75 & 4,19 & 4,64 & 4,52 \\
Ahasverus sp. & 3,40 & 3,46 & 3,41 & 3,42 \\
Corcyra sp. & 2,49 & 2,37 & 2,40 & 2,42 \\
\hline
\end{tabular}




\section{Populasi Serangga Hama}

Pengamatan terhadap populasi serangga hama ternyata Sitophilus oryzae merupakan serangga hama yang memiliki populasi tertinggi yakni mencapai rata-rata 54,60 individu, kemudian diikuti oleh T. castaneum (13,85 individu), Oryzaephilus sp. (4,52 individu), Ahasverus sp. (3,42 individu), C. cephalonica (2,42 individu) dan Carpophilus sp. (6,94 individu), seperti terlihat pada Tabel 1.

Berdasarkan Tabel 1, ternyata jenis serangga dengan populasi tertinggi yang ditemukan pada sampel beras adalah $S$. oryzae $(54,60$ individu). Hal ini menunjukkan bahwa $S$. oryzae merupakan hama utama pada komoditi beras. Serangan hama ini ditandai dengan butir beras berlubang-lubang atau hancur menjadi tepung karena gerekan imago. Akibat serangannya, beras dapat kehilangan berat atau susut berat (Kalshoven, 1981).

S. oryzae menyukai biji yang kasar dan perkembangannya akan terhambat pada bahan makanan yang berbentuk tepung. Kumbang ini tidak akan meletakkan telur pada material yang halus karena imago tidak dapat merayap dan akan mati di tempat tersebut (Marbun dan Yuswani, 1991). Kartasapoetra (1991) menyatakan bahwa serangan kumbang bubuk beras menyebabkan butir-butir beras menjadi berlubang kecil-kecil, sehingga mengakibatkan beras menjadi mudah patah dan remuk menjadi tepung.

Rendahnya populasi serangga hama lainnya seperti $T$. castaneum, Oryzaephilus sp., Ahasverus sp., dan Carpophilus hemipterus diduga karena faktor makanan. Sebagai contoh Tribolium sp. dikenal sebagai hama bubuk, populasinya akan cepat meningkat pada jenis tepung-tepungan atau pada kondisi bahan/materi telah terserang oleh jenis serangga lainnya. Kalshoven (1981) menyatakan bahwa $T$. castaneum merupakan hama sekunder yang berkembang pada bahan yang telah diserang oleh serangga lainnya.

Kalshoven (1981) menyatakan bahwa kumbang gigi gergaji ( $O$. surinamensis) adalah hama utama pada kopra dan jagung. Gejala yang ditimbulkan sama dengan kerusakan akibat kumbang kopra Necrobia rufipes, tetapi lubang gerekannya lebih sempit. Kumbang ini juga dapat merusak padi (gabah). Bagian dada (thorak) kumbang menyerupai gigi gergaji sehingga dinamakan kumbanng gigi gergaji.

Kumbang buah kering (Carpophilus spp.) merusak berbagai bahan dalam simpanan. Kumbang ini jenisnya banyak, contohnya $C$. dimidiatus sebagai perusak buah-buahan kering, $C$. bifestralis dan $C$. flafives yang di Sumatera Utara dikenal sebagai bubuk kopi dan di Sulawesi sebagai perusak jagung dan kopra. Kumbangkumbang tersebut menggerek bahan dan meninggalkan bekas berupa lubang dan butiran bahan sisa gerekan (Kalshoven, 1981). Ngengat beras (Corcyra cephalonica) umumnya menyerang beras giling, namun di Indonesia ngengat beras juga merusak kopra, kacang-kacangan, tepung, dan bungkil. Pengamatan populasi hama pada gudang tradisional ternyata memiliki populasi hama yang lebih tinggi dibandingkan dengan gudang modern, seperti terlihat pada Tabel 2.

Berdasarkan Tabel 2, ternyata populasi hama tertinggi ditemukan pada sampel beras dari gudang tradisional (16,40 individu) dan pada gudang modern (12,34 individu). Relatif tingginya populasi hama pada gudang tradisional diduga disebabkan karena stok beras yang tertampung cukup lama dan tempat penyimpanan yang tidak representatif dibandingkan sampel pada gudang modern. Stok beras yang disimpan pada kondisi gudang yang buruk dapat meningkatkan kadar air beras. Selain itu beras yang tersimpan dalam waktu yang cukup lama memberikan peluang dan waktu bagi serangga untuk melakukan oviposisi pada beras.

Beberapa tempat penampungan beras ditemukan kondisi beras yang tidak utuh lagi yang diduga telah terserang hama terutama pada gudang tradisional, demikian juga dengan kondisi tempat penampungan beras dalam kondisi terbuka. Harahap (2003) menyatakan bahwa beberapa faktor penting yang mempengaruhi perkembangan serangga hama gudang, diantaranya kondisi gudang yang menyangkut kebersihan, dan sistem aerasi udara.

Preferensi serangga terhadap jenis makanan dipengaruhi oleh stimuli zat kimia chemotropisme yang terutama menentukan bau dan rasa, mutu gizi dan adaptasi struktur. 
Tabel 2. Rata-rata Populasi Serangga Hama pada Gudang Tradisional dan Modern

(Table 2. The Average Population of Insect Pests in Traditional and Modern Warehouse)

\begin{tabular}{lccc}
\hline \multicolumn{1}{c}{ Jenis Hama } & \multicolumn{2}{c}{ Tipe Gudang } \\
\cline { 2 - 4 } & Tradisional & Modern \\
\hline Sitophilus oryzea (Col; Curculionidae) & 67,39 & 41,81 \\
T. castaneum. (Coleoptera; Tenebrionidae) & 15,33 & 12,37 \\
Oryzaephilus sp. (Coleoptera; Silvanidae) & 4,14 & 4,90 \\
Ahasverus sp. (Coleoptera; Cucujidae) & 2,84 & 4,00 \\
Corcyra cephalonica (Lep; Pyralidae) & & 4,76 & 1,08 \\
Carpophilus hemipterus (Col; Nitidulidae) & & 3,99 & 9,89 \\
\hline & Total & 98,45 & 74,05 \\
\hline & Rata-rata & 16,40 & 12,34 \\
\hline
\end{tabular}

Tersedianya makanan yang cukup maksudnya adalah yang cocok bagi kehidupan serangga, bila makanan tidak cocok bagi hama dengan sendirinya populasi hama tidak akan dapat berkembang sebagaimana biasanya. Ketidak cocokan makanan dapat timbul karena kurangnya kandungan unsur yang diperlukan, rendahnya kadar air dalam makanan, permukaan material yang keras dan bentuk materialnya (Ebeling, 2002).

\section{KESIMPULAN DAN SARAN}

\section{Kesimpulan}

Terdapat 6 jenis hama pada komoditi beras di Kabupaten Gorontalo, yaitu Sitophilus oryzae, Tribolium castaneum, Oryzaephilus sp., Ahasverus sp., Carpophilus hemipterus, dan Corcyra cephalonica.

S. oryzae, merupakan hama yang memiliki populasi tertinggi yakni mencapai rata-rata 54,60 individu dan terendah $C$. cephalonica rata-rata 2,42 individu

Pada gudang tradisional memiliki rata-rata populasi hama yang lebih tinggi (16,40 individu) dibandingkan gudang modern (12,34 individu).

\section{Saran}

Perlu dilakukan penelitian untuk mengetahui jenis-jenis parasitoid yang menyerang berbagai hama beras di penyimpanan.

\section{DAFTAR PUSTAKA}

Anonim, 2003. Stored Product Management. Oklahoma Cooperative Extension Service
Division of Agricultural Sciences and Natural Resources Oklahoma State University.www.okstate.edu/ag/agedcm4h/ pearl/.

2008. Storage Insects. northshore pest control. http://www.northshorepest control. com.au/storage.html 2009. Rice Weevil ( Sitophilus oryzae ) Australian Wildlife. http://www. ozanimals. com/Insect/Rice-Weevil/Sitophilus/oryzae. $\underline{\mathrm{html}}$

Banks, H.J. 1979. Identification of Stored Product Cryptolestes spp (Col: Cucujidae); A Rapid Techique for Preparation of Suitale Mount. Journal of the Australian Entomology Society, Vol. 18.

Brower, J. 2003. Stored Product Management. Oklahoma Cooperative Extension Service Division of Agricultural Sciences and Natural Resources Oklahoma State University. www.okstate.edu/ag/aged cm4h/pearl/ e912/ch13/ch13f29

Buntin, G. D., S. P. Keith., M.J. Weiss, and James A. Webster, 2003. Handbook of Small Grain Insects. photographs, Maps, and Identification Keys. Entomological Society of America and APS PRESS

Ebeling, W. 2002. Pests Of Stored Food Products. Urban Entomology. Chapter 7. www.entomology.ucr.edu/ebeling/ebeling7

Haines, C.P. 1991. Insect and Arachinids of Tropical Stored Product Their Biology and Identification. Natural Resource Institute, Central Avenue, Chatam Maritime, Kent Mey 4 TB, United Kingdom. 
Halstead, D. G. H, 1986. Key For The Identification of Beatles Associated With Stored Products. Journal of Stored Product Research, Vol 22. No.4 1986.

Harahap, L. H. 2003. Mengenal Lingkungan dan Perkembangan Hama Pascapanen. Balai Besar Karantina Pertanian Belawan. www.bbkpbelawan.deptan. go.id/Hama\% 20Pasca\%20panen.

Hinton, H. E. A A. S. Corbet. 1975. Common insects pests of stored products (A guide to their ideentification). Trustees of fhi British Museum (Natural History). London.

Kalshoven, L.G.E, 1981. Pests of Crops in Indonesia. Revised and Translated by P.A Van der Laan. P.T. Ichtiar Baru - van Hoove, Jakarta.

Kamel, A. H. and Hassaneim, M. H, 1967. Biological studies on Corcyra cephalonica Stainton. Bulletin de la Societé Entomologique d'Egypte, Cairo, 51: 17596.
Manueke, J. 1993. Kajian Pertumbuhan Populasi Sitophilus oryzae dan Tribolium castaneum dan Kerusakan yang Ditimbulkannya Pada Tiga Varietas Beras. Tesis S2 Program Pasca Sarjana Universitas Gajah Mada. Yogyakarta.

Mbata, G. N., 1989. Studies on some aspects of the biology of Corcyra cephalonica (Stainton) (Lepidoptera: Galleriidae). Journal of Stored Products Research, Oxford, 25(4): 181-6.

Munro, J. W. 1986. Pest of Stored. Hutchinson and Co. Ltd. London $45-58$ p.;

Pranata, I. R. 1982. Masalah Susut Akibat Serangan Hama Pascapanen. Direktorat Perlindungan Tanaman Pangan. Coaching Pengendalian Hama Gudang. Cisama. Bogor.

Wagianto, 2008. http://www.fkm.undip.ac.id/data/ index.php?action $=4 \&$ idx $=508$. Diakses pada tanggal 30 Oktober 2009. 
